Journal of English Language Teaching and Applied Linguistics

ISSN: 2707-756X

DOI: $10.32996 /$ jeltal

Journal Homepage: www.al-kindipublisher.com/index.php/jeltal

JELTAL

\title{
A Study on the Techniques of Presenting Vocabulary to Increase Students' Motivation
}

\author{
Phung Thi Thu Ha 8 (i) \\ PhD, Head of Foreign Languages Department, Faculty of International Training, Thai Nguyen University of Technology
}

$\triangle$ Corresponding Author: Phung Thi Thu Ha, E-mail: thuha@tnut.edu.vn

\section{ARTICLE INFORMATION \\ Received: April 08, 2021 \\ Accepted: May 19, 2021 \\ Volume: 3 \\ Issue: 5 \\ DOI: $10.32996 /$ jeltal.2021.3.5.5}

\section{KEYWORDS}

Vocabulary, techniques, EFL, motivation, TNUT

\section{ABSTRACT}

Vocabulary plays an important role in English teaching and learning because it has the notability to stimulate students' participation and help students improve their skills such as listening, speaking, reading and writing. This study was conducted to find out how vocabulary is presented and what factors affect students' motivation in learning vocabulary lesson and thus, suggest some ways of improving the effectiveness of vocabulary teaching and learning at the University of Technology (TNUT), Thai Nguyen, Viet Nam. The data was collected by using two research instruments including questionnaires and interviews. The results showed that both lecturers and students found a lot of benefits from using techniques in presenting vocabulary such as visual aids and verbal means. However, there were some difficulties in teaching and learning new words at TNUT. The research is also believed to be a reliable source of reference for teachers to enhance the effectiveness of using techniques of presenting vocabulary. Hopefully, it will be the springboard for many further studies in the future in the same research field.

\section{Introduction}

There is a unanimous agreement that vocabulary is an important and essential element in learning a second language. (Saleh, 1997, p.12) argued, "the success in mastering a language is determined by the size of the vocabulary one has learned". (Wilkins, 1972 , p.111) said, "Without grammar, very little can be conveyed; without vocabulary, nothing can be conveyed." That is the reason why vocabulary is one of the most important elements of language. By enriching vocabulary, students can gain comprehensive use of English. Although vocabulary plays a prominent role these days, many students have a minimal volume of vocabulary which can prevent them from producing and understanding a large coverage of speech or text. Therefore, vocabulary needs to be learned interestingly and more effectively.

In Vietnam, since the 1990s, teaching English has become a topical issue appealing to the concerns of both researchers and teachers. Vocabulary has been taught within the lesson of reading, speaking, listening, and writing. Most of the students are aware of the importance of learning English in their study as well as in the future job; therefore, they have a great effort in learning. However, their English competence is not the same. Some of them are good and active, while a lot of them are quite passive and unmotivated in learning English. Their knowledge of grammar is acceptable, but their vocabulary is extremely limited. From the survey of the author, it is surprising that many students are only at the beginning level of English. Students usually feel bored in vocabulary lessons because they have not changed their learning habits, such as writing new words on paper, trying to learn by heart or learning passively through the teacher's explanations. They find it difficult to learn and remember vocabulary. Most of them claim that they do not know the best way to learn a foreign language. They don't have a positive attitude towards learning English. The majority of them doesn't have appropriate learning strategies or have an effective habit of learning independently or creatively. As a result, they seem to forget vocabulary quickly, most of them lack a great deal of vocabulary so they can't have a certain source of words to express their ideas in speaking and writing skills.

Regarding the Thai Nguyen University of Technology, most English teachers are energetic and willing to devote their time and energy to teaching. However, their vocabulary teaching methods and strategies are quite different. There are some teachers who

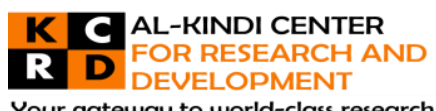

Your gateway to world-class research

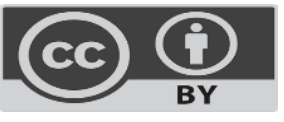

Published by Al-Kindi Center for Research and Development, United Kingdom. Copyright (c) the author(s). This open access article is distributed under a Creative Commons Attribution (CC-BY) 4.0 license 
tend to adopt a communicative-oriented and student-centred approach. They frequently find out the new methodologies and they are flexible in using different vocabulary teaching strategies to different groups of students, whereas some other teachers keep traditional teaching methods. When they introduce new words, they often write new words on the board, then translate them into Vietnamese and make sentences with them. They read aloud first. Then students repeat the words in the chorus. Then they ask some students to read the words individually. Sometimes the teacher shows some pictures on the projectors to illustrate new words. Furthermore, many students at Thai Nguyen University of Technology usually learn vocabulary passively through teachers' explanation. They try to learn vocabulary by heart and they rarely use them in communication. As a result, the vocabulary learning activities are neither interesting nor motivating. Then, students' vocabulary competence is not widened, and vocabulary teaching and learning are not effective as expected.

To motivate students in vocabulary lessons, and to achieve more effectiveness from vocabulary teaching techniques, the research was conducted to find the answer to the following research questions:

1. What types of vocabulary presenting technique are used in vocabulary lessons at TNUT?

2. What factors affect students' motivation in learning vocabulary lessons at TNUT?

3. What techniques should be applied to increase students' motivation in vocabulary lessons at TNUT?

\section{Literature Review}

\subsection{The role of vocabulary in language teaching and learning}

It cannot be denied that vocabulary plays a significant role in language as many aspects of learning vocabulary have been studied, including vocabulary use, vocabulary course design, evaluation, and vocabulary learning strategies. Without a large vocabulary, it is difficult to hold a proper conversation. Vocabulary knowledge is often viewed as a critical tool for second language learners because a limited range of vocabulary in a second language impedes successful communication. Underscoring the importance of vocabulary acquisition, Schmitt (2000) emphasized that "lexical knowledge is central to communicative competence and the acquisition of a second language" p. 55).

Folse (2014) expresses that "learning a language entails learning numerous aspects about that language, including its pronunciation, writing system, syntax..., but the most important aspect is vocabulary". Therefore, vocabulary is considered a useful part and fundamental tool for communicative purpose and acquiring knowledge.

Nation (2001) further described the relationship between vocabulary knowledge and language use as complementary: knowledge of vocabulary enables language use and, conversely, language use leads to an increase in vocabulary knowledge. Commenting on the role of vocabulary, Wilkins (1982), a famous British linguist, said: "Without grammar, very little can be conveyed, without vocabulary, nothing can be conveyed". (2002:35).

Moreover, Carmen (2005) states that vocabulary is crucial for getting meaning from a written or oral text. Without knowledge of key vocabulary in a text, students may have difficulty understanding the message.

In conclusion, vocabulary teaching and learning is a complicated and laborious process. For every language learner, it is essential to acquire the language components of a language before developing the language skills. Therefore, it cannot be denied that the role of vocabulary in language teaching and learning is extremely significant.

\subsection{Techniques in presenting vocabulary}

Teaching vocabulary can be divided into three stages: presenting stage, practising stage and revising stage. In this study, the author only mentions the first stage of teaching vocabulary. Presenting stage is considered to be the most important stage in teaching vocabulary. Teachers have to convey and help students understand the meaning, spelling, usage and pronunciation of the new words. It is necessary for teachers to adopt different techniques to motivate and attract students into the lessons.

Ur (1996) suggested ten ways of vocabulary presentation for the meaning of new items: "concise definition, detailed description, examples, illustrations (such as by pictures and objects), demonstration (acting, mime), context, synonyms, antonyms, translation and associated ideas or collocations". Also, other ways were suggested by Allen (1983) in presenting vocabulary. These techniques are applied to different levels of learners from beginners to advanced learners. He stated that using visual aids, real objects and dictionaries can be of great help for vocabulary teaching. $\mathrm{Nu}$ (2004) supported this idea by Allen by giving 8 ways of presenting a new word such as by using visual aids, realia, actions or gestures, situations or explanations, synonyms/antonyms, examples, translations and combining a variety of techniques along with suggested questions. These are some techniques used in the presentation of new vocabulary items by Gairns and Redman (1986).

\section{Visual techniques}

These techniques show the meaning of the word visually. This is the most common way in the stages to present the meaning of a new word. There are different types of visual aids that help language teachers facilitate their teaching process. According to 
Gains and Redman (1986), these techniques can include flashcards, photographs, blackboard drawings, wall chart, realia, facial expressions, gestures and mine. These techniques attract the students, gives them the comfort to study and helps students associated material in a meaningful way.

Flashcard and pictures are very useful tools which are used presenting vocabulary. Rijavec (1991:51) states that " Pictures can be employed to enrich the context, add vividness and reduce boredom". In presenting new words, flashcards and pictures allow learners to brainstorm and present their ideas on thought. Teachers find flashcards and pictures on magazines, newspapers, textbooks or the Internet.

Realia refers to real objects which are around or brought into the classroom and used for teaching and learning. Using realia is an effective way of presenting new words. Realia illustrates meaning more directly and quickly than through verbal explanation.

Using gestures and mime is a useful and effective way of introducing words since it can promote students' understanding and meaningful retention of new items. This technique creates good brainstorming, develops students' imagination and observation ability. Visual support helps learners understand the meaning and helps to make the word more memorable. In addition, students often feel comfortable and relaxed while learning vocabulary with the help of visual aids. Students have a chance to get involved in the lesson. When teachers use visual aids such as pictures, real objects, facial and gesture expression, etc., will create an enjoyable atmosphere in the classroom. Students can observe the visual aids, listen to the teacher's explanation and guessing the meaning of the new words.

In conclusion, visual aids are extensively used for conveying meaning and are useful for teaching concrete items of vocabulary such as food, jobs, sports or furniture or daily activities, etc. These techniques are attractive to get students involved in the lesson.

\section{Verbal techniques}

This is one of the most important techniques to present new words. This technique is commonly used to help students understand more about abstract words. It consists of the use of definition, synonym, antonym and translation. The teacher can use definition and illustrative sentence (the use of other words in the same language) to offer the advantage of con-tantalization and show how the new words are used. However, it may be difficult for the students to understand definition because they may contain words, which students do not know.

Using synonyms and antonym is an effective way to widen and develop students' vocabulary because, with this technique, teachers explain the meaning of new words by giving them similar and the opposite meaning. It will help students remember the words better when they know how the meaning of a word relates to the meaning of other words. It also helps students build a new vocabulary based on the words they already know. Shortly, it is a useful technique to attract students' attention.

\section{Context building}

This is probably a very useful technique because it gets students to work out the meaning of words for themselves. The context plays a large role in helping the students learn new vocabulary and in establishing how words are actually used in speech and writing. The teacher should think of a clear context when the word is used. The teacher can also describe the context to the students or give them example sentences to clarify the meaning. The best way to remember words is by using them in many different contexts.

\section{Translation}

This is sometimes considered to be a traditional way but turns out to be an effective use in the classroom context. Showing the meaning of new vocabulary by using translation can be quicker and easier for teachers so that they can spend more time on other activities.

According to Komarowska (2005) " translation is advisable when introducing abstract words". The translation is suitable to explain the difficult words. This technique is simple and easy to understand, and it also saves time in the classroom. However, translation brings some negative effects because it may limit reduce the use of a second language in class.

\subsection{The importance of motivation in language teaching and learning}

It is clear that motivation is one of the main factors which influence the rate and success of language teaching and learning. Moreover, motivation provides the primary impetus to initiate learning a language. Motivation determines the extent of active, personal involvement in the learning process. Conversely, without sufficient motivation, even individuals with the most remarkable abilities cannot accomplish long-term goals, and neither are appropriate curricula and good teaching enough on their own to ensure students achievement (Dörnyei Z. (2001a). 
Reece and Walker (1997 as cited in Gomleksiz 2001) express that motivation is a key factor in the second language learning process. They stress that a less-able student who is highly motivated can achieve greater success than the more intelligent student who is not well motivated. Sometimes students may come highly motivated, and the task of the teacher is to maintain the motivation of the students.

Motivation has an important role in success and failure in learning a second language. Spolsky (1990) stated that motivated students are likely to learn more and learn more quickly than students who are less motivated. In a particular learning situation, less motivated students are likely to lose their attention, misbehave and cause discipline problems. On the contrary, students who are more highly motivated will participate actively and pay more attention to a certain learning task or activity.

Reece \& Walker (1997 as cited in Gomleksiz 2001) express that a less-able student who is highly motivated can achieve greater success than the more intelligent student who is not well motivated. It is very difficult to convey a second language in a learning environment if the learners do not have a desire to learn it. Sometimes students may come highly motivated and the task of the teacher is to maintain the motivation of the students.

\subsection{Factors affecting students' motivation in vocabulary lessons}

Motivation has a great significance in language learning and teaching in general and in teaching vocabulary in particular. Vocabulary plays a vital role in language learning, so it is essential that learners know a number of vocabulary to acquire different language skills at a certain level such as speaking, listening, reading and writing. In order to motivate students in vocabulary lessons, the teacher needs to know what factors affect students' motivation while they are dealing with their new vocabulary in a vocabulary lesson. There are many factors that affect students' motivation in vocabulary learning. According to Harmer (1991, p.4), there are four factors that affect the learners' motivation as follows.

\section{Physical condition}

Physical condition means the atmosphere and condition of the classroom. If we do not have good conditions for teachers to teach, for students to learn, it is not easy for them to get the best result as well as the effectiveness in teaching and learning. For example, if students have to study in a bad lighting classroom, overcrowded with too many students, have to look at the small board, they can lose their motivation or their motivation in learning will be lowered.

Nowadays, with the development of technology and the demand of students and teachers in teaching and learning are higher and higher, many modern types of equipment are equipped for each classroom such as the projector, the laptop, the speaker and cassette player. They are really useful equipment in teaching and learning.

\section{Method of teaching}

Teacher's teaching methods are very important because they can demotivate or motivate students to get involved in learning activities. The teacher's methods are also among the most significant factors affecting student's motivation in a vocabulary lesson. It refers to the way that students are taught must affect their motivation. When the learners show less interest in the lesson than usual, their motivation would likely be lost or gradually decreased. As he said, "If the students lose confidence in the method, they will become demotivated" (Harmer, 1991, p. 5). The method of teachers should be changed usually so that it's suitable for the learning style of the students. It seems that the students will be bored with learning and do not want to learn any more if the teachers often use traditional methods to teach. Besides using the books and material just related to the lesson in accordance with the teachers' book, the teachers should find and introduce extra books and material to students. Teachers should always update new methodology, study and advance their knowledge to meet the needs of students.

\section{The teachers}

The importance of the teacher factor in having a high level of motivation in second language acquisition cannot be neglected. The success of a teacher in second language acquisition in school directly affects the success of learners. The more successful the teacher is in focusing and facilitating effective pupil calibration, the more effective the teacher will be in facilitating effective pupil learning. The teachers as the most powerful variable of motivation and demotivation, can become a major part in demotivating the learners.

Teachers who have teaching experience, enthusiasm, willingness to innovations and new methodological approaches will bring interesting and effective lessons to learners. Other factors that influence the students' attitudes and motivation in the language learning class are the teacher's personality traits and the teacher's behaviour in class (Madrid,1993). So, teachers should be always pleased, friendly and willing to help students with their learning problems.

Success 
Success refers to the appropriate level of challenge designed by the teachers. If the difficulty of work and activity is too high or too low, it can lead students to a demotivated situation in learning. As Harmer pointed out, giving high challenge activities may have a negative effect on motivation. Students can also equally be demotivated by a too low level of challenge.

Besides these factors, there are some factors affecting students' motivation such as tiredness, depression, anxiety, boredom, etc., may obstruct the learning process of the students. This means that learners' emotion can affect their motivation. In addition, teaching materials also affect students' motivation. The materials provide the content of the lesson, the balance of skills taught, and the kind of language practice students take part in. Suitable materials will enhance students' motivation in vocabulary lessons.

\section{Methodology}

To find answers to the research questions, the study used a combination of qualitative and quantitative research approaches, which include document analysis and survey questionnaires, interviews.

\subsection{Subjects of the study}

The participants are categorized into two groups.

The first group involves 15 teachers of English ranging from 30 to 50 years old. All of the teachers have been teaching English for at least five years at Thai Nguyen University of Technology, so they have enough experience to teach English. Of these teachers, one has a PhD degree and all the others are Masters of Art in English Teaching Methodology and English Language. When teaching vocabulary, they know how to use a variety of activities to encourage students to take part in the lesson.

The other group includes 95 first year non-majored students at Thai Nguyen University of Technology. Some students are good at learning English, but many others find it difficult to learn and remember the vocabulary. In general, most students know how to use basic grammatical knowledge. However, they own an insufficient amount of vocabulary and they do not have an effective method to learn new words. Therefore, the researcher would like to find out their attitude towards vocabulary learning, their current methods to learn vocabulary, the difficulties and the factors that affect their learning motivation.

\subsection{Data collection instruments}

To obtain data for the study, the author used two methods including questionnaires and interviews to collect reliable and useful data for the study. The combination of the two methods listed previously allows the researcher to answer all three research questions thoroughly. It was carefully calculated that each method was used in order to support the others.

\section{Questionnaires}

To gain the data for the research, two questionnaires were administered to the respondents. One was designed for the teachers and the other for the students. This method was chosen because it is convenient to construct, and it is extremely versatile and uniquely capable of gathering a huge amount of information in a short time (Dornyei).

The questionnaires were delivered to 15 teachers and 95 students. After carefully examining the available instruments and basing on certain knowledge about learners, the author designed these questionnaires to get information as follows:

- Students' attitude towards vocabulary learning

- Students' styles in learning vocabulary

- Students' comments on their teachers' techniques in presenting vocabulary and their expectation

- Teachers' attitude towards the role of vocabulary in language teaching and their difficulties in teaching vocabulary at TNUT

- Teachers' current techniques in presenting vocabulary

- Techniques used by teachers to increase students' motivation

\section{Interview}

Interview is considered a technique used to understand the experiences of others. It has been called the primary method used in qualitative research (Burnard, 1994; Doody \& Noonan, 2013; Myers \& Newman, 2007; Ryan, Coughlan \& Cronin, 2009) and "the most direct, research-focused interaction between research and participant" ( Kazmer \& Xie, 2008, p.258; see also Kvale, 1996). In this study, interviewing was used to obtain teachers' current method of vocabulary teaching, the challenges and what techniques should be used to increase students' motivation.

\subsection{Data analytical method}

The data was collected through questionnaires and interview. The data obtained from questionnaires were easily analyzed by using the application of Google Drive and Microsoft Excel application. The results were collected and analyzed with the support of charts. 


\section{Results and Discussion}

\subsection{Result from the questionnaires}

\section{Teachers' attitude towards the role of vocabulary teaching in language teaching}

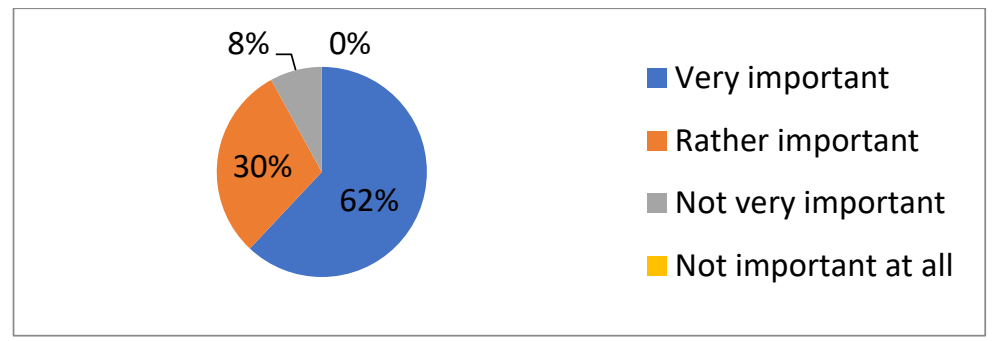

Figure 1: Teacher's attitudes towards the role of vocabulary teaching in language teaching

As can be seen from the chart, $62 \%$ of the surveyed teachers appreciated the importance of teaching vocabulary in language teaching. They said that it was very important to teach vocabulary to learners, but $30 \%$ of them have lessened the importance of teaching new words to their students, while $8 \%$ of the teacher thought teaching vocabulary was not very important.

Teachers' current methods in presenting vocabulary

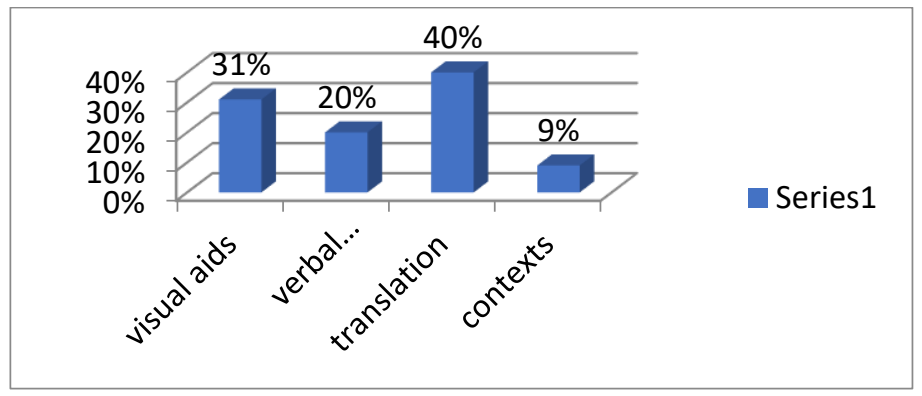

Figure 2: Teachers' current methods in presenting vocabulary

Regarding the available methods, it can be recognized that $40 \%$ of surveyed teachers always use the translation for vocabulary teaching. They show that translation is a traditional way but it is an effective technique that is used in the classroom context. $31 \%$ of the surveyed teachers use visual aids for their vocabulary teaching. They reveal that using visual aids such as pictures, realia and mimes can convey the meaning clearly and help students understand the meaning better. The numbers of participants who usually use verbal means in presenting vocabulary accounts for $20 \%$. Whereas $\overline{\bar{T}}_{\bar{T}}$ the number of the surveyed teachers that use contexts and explanations makes up only $9 \%$. The reason can be that students find it difficult to guess the meaning of the words through the contexts because of their limited vocabulary.

\section{Students' reflections about teachers' current techniques of presenting new words}




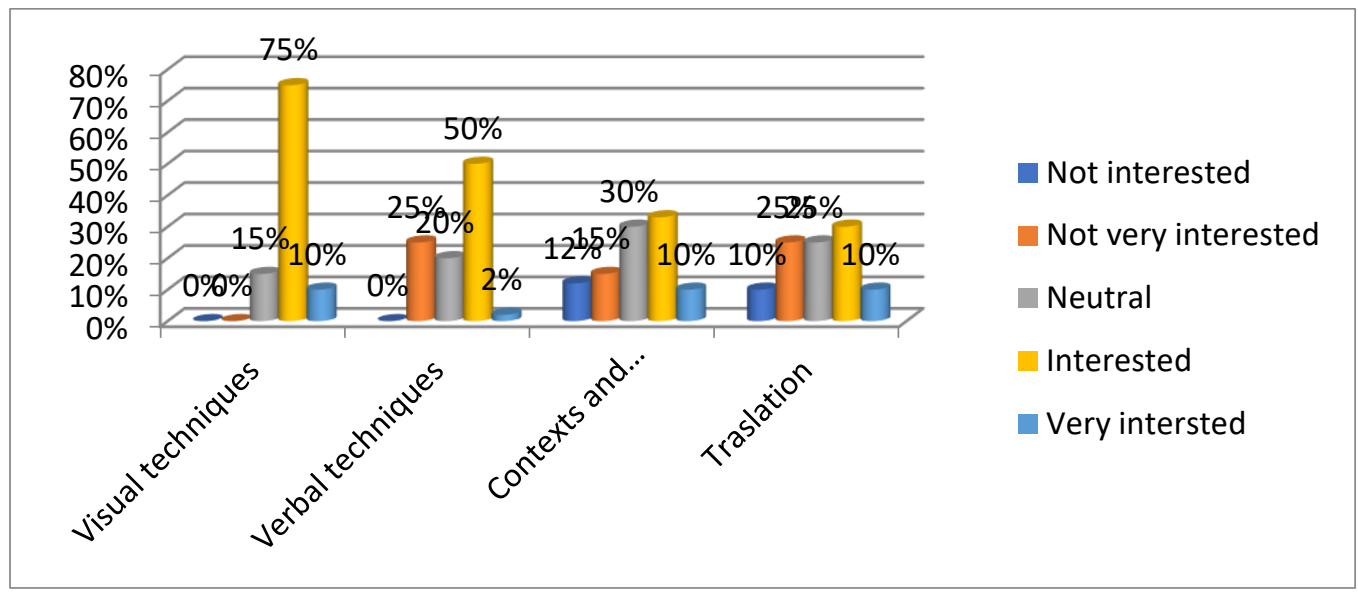

Figure 3: Students' reflections about teachers' current techniques of presenting new words

The above figure presents the impressions of techniques used by the teachers in presenting new words to the students. Most of the visual aids appear interesting and motivate students (75\%). In addition, using verbal means such as the use of definition, synonym and antonym also attract students' interest. However, students find bored with the way their teachers translate all new words into Vietnamese (25\%).

\section{Factors affecting students' motivation in the vocabulary lesson}

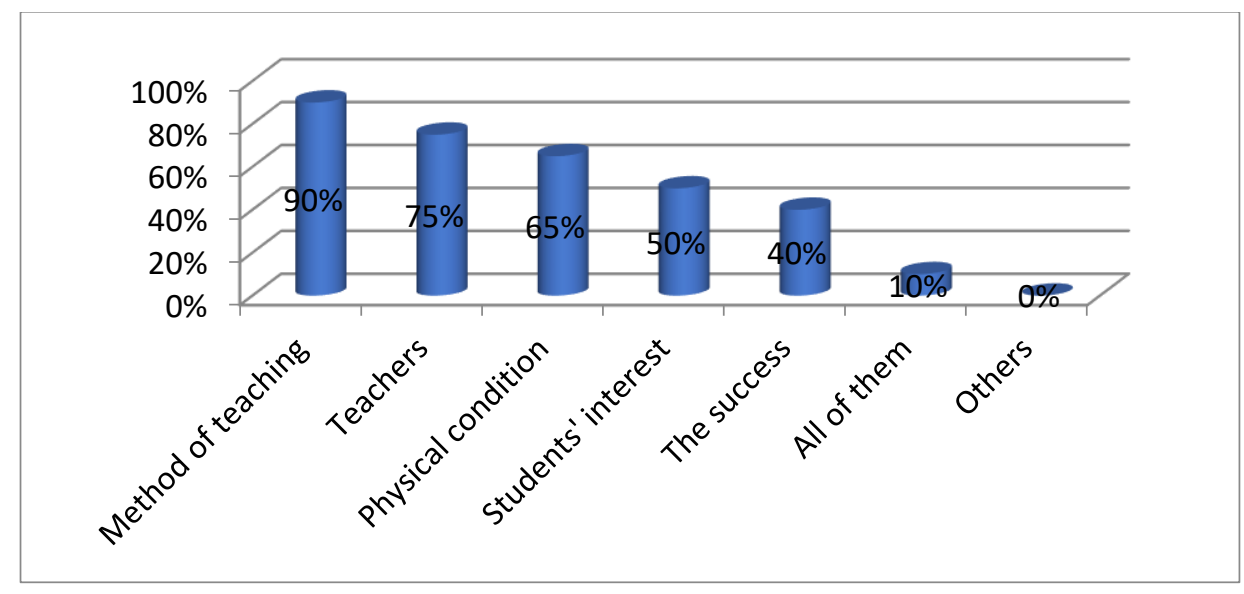

Figure 4: Factors affecting students' motivation in the vocabulary lessons

It can be seen from the above figure there is a high level of agreement about the method of teaching has a strong effect on students' motivation in learning English vocabulary. Most of the teachers (90\%) consider that students will feel excited to join the vocabulary learning process if the teacher uses appropriate and interesting methods in each lesson. Moreover, the results indicate that teachers affect directly the motivation as well as the success of learners. Teachers who are always pleased, friendly and willing to help students with their learning problems have a positive influence on students' motivation.

$65 \%$ of the surveyed teachers reflect that the physical condition such as classroom and the atmosphere of the class bring the motivation for the learners. Classroom using projectors, laptops... and connected with the Internet, the speaker and cassette player can enhance the effectiveness of vocabulary learning. If students have to study in a bad lighting classroom, overcrowded with too many students they can lose their motivation in learning.

In addition, 50\% of the teachers say that students' interest is an important factor that stimulates students in the learning process. It means that the learners find learning a language interesting and they are willing to learn it. 40\% of the teachers think that success also affects students' motivation in vocabulary. Success refers to the appropriate level of work and activity designed by teachers. If the activity is not suitable, it can lead students to a demotivated situation in learning. And the teachers who suppose that all of these factors affect students' motivation account for only $10 \%$.

Teachers' current methods to increase students' motivation in the vocabulary lessons 


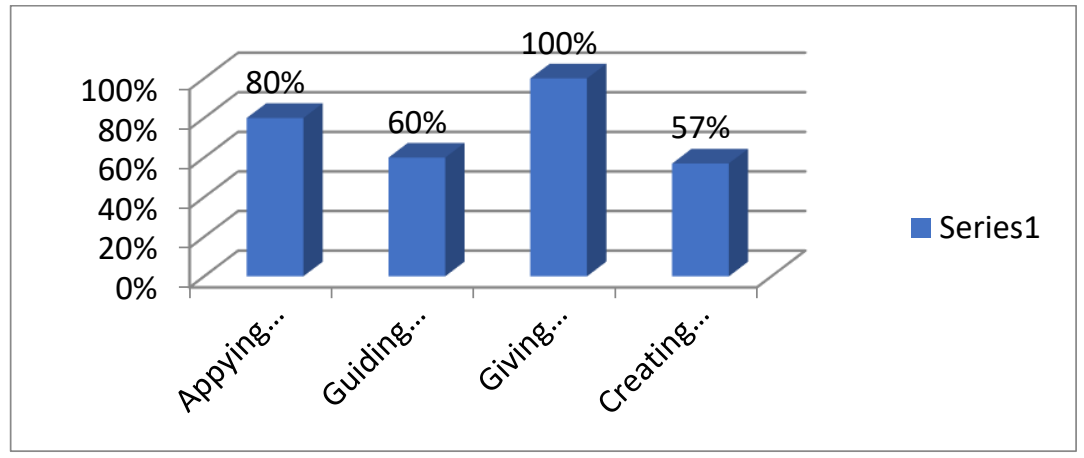

Figure 5: Teachers' current methods to increase students' motivation in the vocabulary lessons

Figure 5 indicates the teachers' current methods in language teaching to increase students' motivation in a vocabulary lesson. All of the surveyed teachers often give students good marks, rewards and compliments to stimulate students' motivation. Getting good marks always makes students more enthusiastic in the learning process. Giving students compliments make them more confident in language class. $80 \%$ of asked teachers often apply information technology such as projector, laptop, smartboard in presenting vocabulary to attract students' attention. They share that when showing pictures or video clips on the projector, students take part in the lesson more enthusiastically. $60 \%$ of the teachers often guide students to learn positively and effectively to help students more confident in learning vocabulary. In addition, 56\% of the surveyed teachers state that they usually create a happy and friendly atmosphere in class to make their vocabulary lessons more interesting.

\section{Students' attitudes towards vocabulary learning}

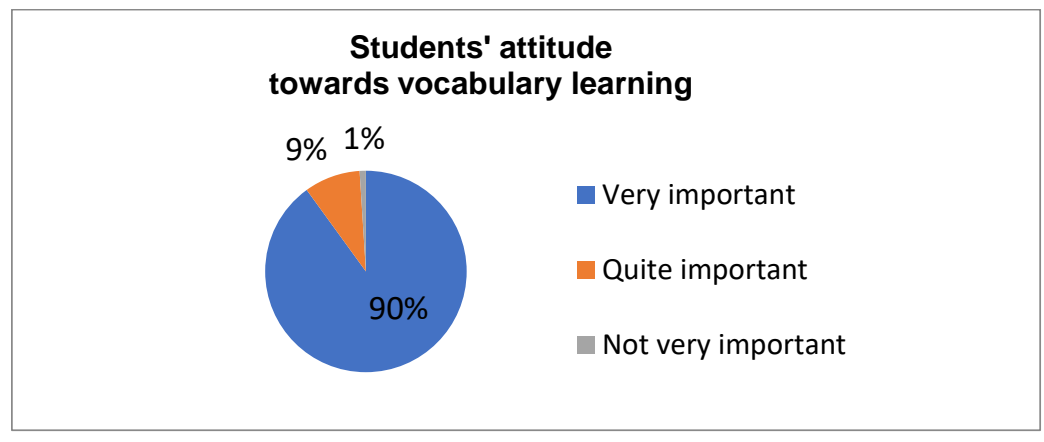

Figure 7: Students' attitudes towards vocabulary learning

It can be seen from Figure 7 that there is a high level of agreement about the important role of vocabulary in teaching and learning English. Most of the respondents (90\%) considered vocabulary a very essential element in language learning. Only $9 \%$ of the students think vocabulary is quite important and $1 \%$ of them thinks that vocabulary is not very important. The result also shows that the students are quite aware of the necessity of vocabulary in learning English. It is expected that this clear awareness is supposed to increase the students' motivation in learning English.

\section{Students' current methods to learn new words}

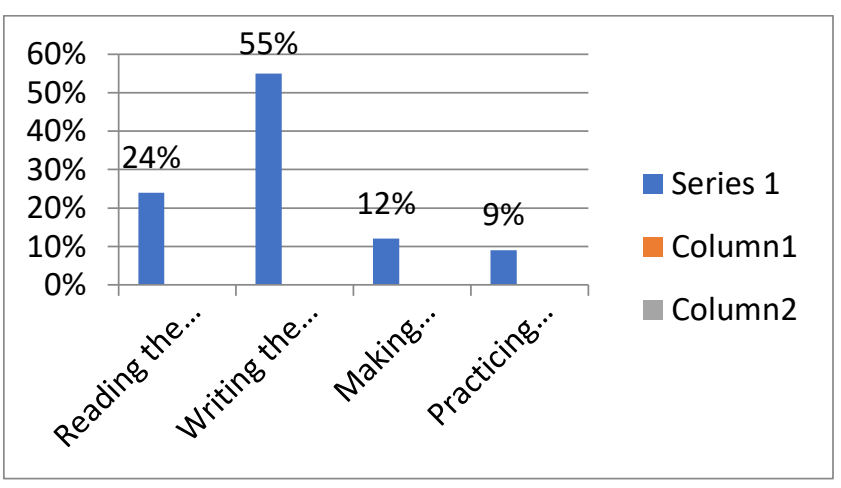

Figure 8: Students' current methods to learn vocabulary 
The result showed that most of the students (55\%) had the habit of learning vocabulary by writing the words in English many times. This can be explained by the fact that they often concentrate on the spelling and the pronunciation of the words because they think that remembering the spelling and pronunciation of new items is very important. In addition, $24 \%$ of the respondents learn new words by reading them many times. Only $12 \%$ of them learn new words by making sentences with new words. Students say that it is quite difficult to make sentences with the new words because they lack vocabulary, and they are not confident about grammatical items. Only a few of them (9\%) learn vocabulary by practising vocabulary exercise. They think that learning vocabulary simply is to memorize the spelling and the meaning, so they do not care about using them in context and doing vocabulary exercises.

\subsection{Results from the interviews \\ Opinions of the necessity of teaching vocabulary before each skill of language.}

According to all interviewed teachers, they all shared the ideas that it is necessary to teach new words before each skill in order to help students understand the content of the lesson and do the task. They expressed the importance of teaching vocabulary in language teaching because vocabulary appears in every language skill. They all agreed that students can perform well in speaking, reading, writing and listening if they possess a rich vocabulary. Learners can read and understand the text quickly and develop listening skills if they have a wide range of vocabulary.

\section{The major challenges teachers encounter when they present their students' vocabulary}

Having many activities to finish in a period, teachers faced up with the lack of time to do the teaching. All of them wished to have more time and reduce the content in a lesson because in some lesson there are many new words. The interviewed teachers also wanted to have enough teaching equipment such as pictures, flashcards, posters available in the school library. One of them expressed that the limited vocabulary of students and the unequal level of them prevented her from applying some effective techniques. Two of the four teachers also shared that many students are lazy, passive and lack motivation in learning.

\section{Teachers' current techniques in presenting vocabulary}

The third concerned aspect is teachers' methodology. It is found that the teachers use different techniques in presenting vocabulary. From the interview, using translation and pictures are the most frequently used by most teachers in presenting new words. According to teachers, the advantages of the translation technique are time-saving, easy to understand. Teaching vocabulary through pictures is also applied frequently by teachers. They said that they often searched pictures on the internet and inserted them into slides to present on the projector. Only one teacher shared that she sometimes used real objects or context in the classroom to present vocabulary. All these techniques are effective and make the lesson more interesting.

\section{The effectiveness of students' vocabulary learning}

With the current techniques, half of the interviewed teachers found that it is effective because their students were very excited when they showed the pictures, posters and real objects. However, two teachers shared that they didn't have enough time and good facilities, so teaching vocabulary is not very effective. Students seemed to be passive and bored when teachers usually use traditional methods. Shortly, to attract students' attention teachers should change suitable techniques and update new methods.

\section{Activities that enhance their students' motivation in vocabulary learning lessons}

In order to enhance students' motivation, all of the interviewed teachers shared that they check new words regularly. They often encouraged students to take part in learning activities. Of four teachers, two teachers expressed that they give their students compliments, rewards (good mark) or punishment. One teacher expressed that she would combine the techniques to meet the students' need. Two of the four teachers shared that they would organise games and competitions to stimulate students' motivation.

\section{Implications and suggestions for teaching and learning English}

In language teaching and learning, it is necessary to apply an appropriate method and technique. It can be seen from these result findings that to make the teaching-learning process successful, the teacher is not only the source of the knowledge and dominates the learning process. She or he should create a situation where the students are involved in experiencing learning.

Firstly, it is suggested that the teachers should pay more attention to teaching vocabulary by applying more interesting vocabulary teaching techniques such as visual aids, verbal means, ...to attract students' attention. It is essential to change and combine techniques to have a successful vocabulary teaching lesson. Visual aids such as pictures, real objects, facial gestures should be used regularly to draw students' attention.

Secondly, it is necessary for teachers to combine textbook with other materials such as newspaper, magazines, videos, dictionaries, postcards, TV programs, etc. Teachers should prepare and select materials that suitable for each class and students' level. They should adapt and design suitable activities to enhance students' motivation. 
Thirdly, teachers also should pay attention to the importance of motivation in English class and know how to increase students' motivation. Besides that, they should also know the factors that affect the vocabulary learning of students to inspire the passion for learning English.

Fourthly, teachers should share and discuss the experience with colleagues to improve their teaching methods and find out effective vocabulary teaching techniques. Each teacher needs to widen and raise their knowledge to meet the development of education.

Finally, the learning atmosphere and teachers' mood are very important for increasing students' motivation and interest in a lesson so teachers can apply humour activities with friendly talks, funny stories in teaching vocabulary and express their help in any case. If the atmosphere of the class is friendly, happy, communication in class will be effective.

In conclusion, this study can be a reference for the teachers in improving the quality in applying the effective technique toward improving the students' learning motivation and achievement in learning English.

Funding: This research was funded by Thai Nguyen University of Technology.

Conflicts of Interest: The authors declare no conflict of interest.

\section{References}

[1] Allen, VF (1983). Techniques in Teaching Vocabulary. Oxford University Press.

[2] Brown, H.D. (2001). Teaching by Principles: An Interactive Approach to Language Pedagogy (second edition). New York, Addision Wesley Longman, Inc.

[3] Doody, Owen \& Noonan, Maria (2013). Preparing and conducting interviews to collect data. Nurse Researcher, 20 (5), $28-32$.

[4] Dörnyei, Z. (2001a). Motivational strategies in the language classroom. Cambridge University Press.

[5] Folse (2014). Myths about teaching and learning second language vocabulary: What recent research says. TESL Reporter, 37 (2).

[6] Gairns, R \& Redman, S. (1986). Working with words. Cambridge University Press.

[7] Gardner (1982). Social psychology and language learning. The role of attitudes and motivation. London: Edward Arnold.

[8] Harmer, J. (1991). The Practice of English language Teaching. Essex: Longman.

[9] Hornby, AS. (1994). Oxford Learner's Dictionary. Oxford: Oxford University Press

[10] Kim, S. \& Kim, M. (2012). Kolb's learning styles and education outcome. International journal for education media and technology, 6 (1), 413

[11] Lighbown, S. (1999). How languages are learned. Oxford Univerity Press.

[12] Maslow, A. (1970). Motivation and personality. New York: Harper and Row.

[13] Nation, (2001). Learning vocabulary in another language. Cambridge University Press.

[14] Nunan, D. (1992). Research methods in Language Learning. Cambridge University Press.

[15] Parsons, R., Hinson, S., Brown, D. (2001). Educational psychology: practitioner-researcher models of teaching. University of Virginia: Wadsworth Thomson Learning.

[16] Taylor, L. (1990), Teaching and Learning Vocabulary. New York: Prentice-Hall.

[17] Thornbury, S. (2002). How to teach vocabulary. United Kingdom: Pearson Educational Limited.

[18] Ur, P. (1996). A Course in Language Teaching: Practice and Theory. Cambridge: Cambridge University Press

[19] Wilkins, (1982). Linguistic in language teaching. London: Edward Arnold 